\title{
The Effect of Beliefs in a just World on Defending Behavior Against Bullying Among Upper Elementary Students and the Moderating Role of Classroom Climate
}

\author{
Seung-chul Lim ${ }^{1}$, Ju Hee Park ${ }^{2}$ \\ M. A., Department of Child \& Family Studies, Yonsei University, Seoul, Korea ${ }^{1}$ \\ Professor, Department of Child \& Family Studies, Yonsei University, Seoul, Korea ${ }^{2}$ \\ 초등학교 고학년의 공정성에 대한 믿음이 또래괴롭힘 방어행동에 \\ 미치는 영향과 학급분위기의 조절효과 \\ 임승철 ${ }^{1}$ 박주희 ${ }^{2}$ \\ 연세대학교 아동·가족학과 석사 ${ }^{1}$, 연세대학교 아동·가족학과 교수 ${ }^{2}$
}

\begin{abstract}
Objectives: The purpose of the current study was to examine the influences of beliefs in a just world and classroom climate on defending behavior and investigate whether classroom climate moderated the relations between beliefs in a just world and defending behavior.

Methods: The participants were 194 children, $4^{\text {th }}$ to $6^{\text {th }}$ graders from 11 elementary schools. The data were analyzed by means of descriptive statistics, Pearson's correlation coefficients, and a hierarchical multiple regression. The moderating effects were explored using Johnson-Neyman technique.

Results: The outcomes of this study indicated that both belief in a just world for others and classroom climate had positive effects on defending behavior. The higher the level of belief in a just world for others, and the less likely to permit bullying the classroom, the more likely to show defending behavior the students. However, belief in a just world for self had no significant effect on depending behavior. In addition, classroom climate moderated the relation between belief in a just world for self and defending behavior; the effect of belief in a just world for self on defending behavior was greater when the level of classroom climate accepting bullying was low, compared to when it was high.

Conclusion: The result suggested that it could be an effective way to help students develop the belief that the world they live in is fair toward themselves and others. Also, it would be necessary to create classroom climates in which bullying is intolerable to encourage students' defending behavior.
\end{abstract}

Keywords: elementary student, defending behavior, belief in a just world, classroom climate

\section{Introduction}

어려움을 겪는 사람에게 가까운 지인의 도움은 큰 힘이 될 수 있다. 특히 학급 내에서 발생하는 또래괴롭힘의 피해를 겪

Corresponding Author: Ju Hee Park, Professor, Department of Child \& Family Studies, Yonsei University, 50 Yonsei-ro, Seodaemun-gu, Seoul, Korea

E-mail: juheepark@yonsei.ac.kr
는 아동은 이를 목격하는 학급 구성원의 지원을 받을 수 있을 때 보다 수월하게 어려움을 극복할 수 있다. 그러나 Ministry of Education (2018)의 보고에 따르면 또래괴롭힘을 목격하고 도 아무런 행동을 취하지 않는 아동의 비율이 $30.5 \%$ 인 것으

(C)The Korean Association of Child Studies

This is an Open Access article distributed under the terms of the Creative Commons Attribution Non-Commercial License (http:// creativecommons.org/licenses/by-nc/4.0) which permits unrestricted noncommercial use, distribution, and reproduction in any medium, provided the original work is properly cited. 
로 나타났다. 또한 대부분의 아동이 또래괴롭힘이 옳지 않은 일임을 인지하면서도 실제로는 도움을 주지 않는 경우가 있어 (O'connel, Pepler, \& Craig, 1999) 또래괴롭힘을 중재하기 위해 학급 전체를 대상으로 하는 개입의 필요성이 제시되고 있다. 특히 점차 친구관계의 중요성이 커지는 초등학교에서 또래괴 롭힘 피해응답 비율이 중.고등학교에 비해 많이 나타나며 또 래괴롭힘을 처음으로 목격하는 경우가 초등학교 고학년 시 기에 가장 많다는 점은(J. Lee, Kim, Cha, Lee, \& Park, 2018; C. Lim \& Chung, 1997; Ministry of Education, 2018) 초등학교 고 학년 아동들 사이에서 나타나는 또래괴롭힘을 중재하기 위한 방안이 필요함을 시사한다.

Lagerspetz, Björkqvist, Berts와 King (1982)은 이와 같은 또래 괴롭힘이 단순히 가해자, 피해자의 양자 간 문제가 아니라 집 단 내 역동 속에서 나타난다고 주장하며 또래괴롭힘의 문제 를 다루는 데에 있어서 괴롭힘에 직접 참여하지는 않지만 이 를 목격하는 주변인의 역할을 적극적으로 고려할 필요가 있음 을 강조한 바 있다. 실제로 또래괴롭힘 중재 프로그램의 효과 에 대한 메타분석 결과(Ttofi \& Farrington, 2011) 가해자와 피 해자만을 대상으로 하는 프로그램은 효과가 없었다는 결과가 제시되어 주변인 역할의 중요성을 지지하고 있다. 관찰이나 자기보고를 통해 교실 내 또래괴롭힘 상황을 관찰한 선행연구 들에서도(Cha \& Park, 2011; Hawkins, Pepler, \& Craig, 2001) 대 부분의 학급 구성원들이 또래괴롭힘 상황에 여러 가지 역할로 관여하고 있는 것으로 나타나 또래괴롭힘 주변인들의 행동을 이해하고 피해자에게 도움이 되는 행동의 예측요인을 파악하 는 것이 또래괴롭힘을 효과적으로 예방하는 방안을 고안하는 데 도움이 될 수 있음을 보여주고 있다.

Salmivalli, Lagerspetz, Björkqvist, Österman과 Kaukiainen (1996)은 또래괴롭힘 주변인의 행동을 네 가지로 구분하였는 데, 구체적으로 가해자가 가해행동을 지속하도록 하는 강화 자(reinforcer)와 조력자(assistant), 아무런 행동도 하지 않는 방 관자(outsider), 피해자를 방어하는 방어자(defender)이다. 이 중 방어자는 피해자를 지지하거나 위안을 주고 가해자의 가해행 동을 제지하는 역할을 하기 때문에 Salmivalli 등(1996)은 방어 자가 또래괴롭힘을 예방하는 데에 기여할 수 있다고 주장하였 다. 이러한 가능성을 검증한 연구들은 방어행동이 피해자뿐만 아니라 방어자 자신에게도 긍정적인 영향을 미침을 보여주고 있다(Ma \& Chen, 2017; Shon \& Lee, 2015). 또래괴롭힘 피해 자의 경우 방어자의 행동으로 인해 우울과 불안 수준이 낮아 졌으며 방어행동을 보인 방어자는 자신감이 향상되고 보다 더 적극적으로 도움행동을 보이려는 태도를 가지게 된 것으로 나
타났다. 뿐만 아니라 방어자가 피해자를 돕고 가해자에게 대 응함으로써 가해자의 가해행동이 억제되었다는 연구결과도 제시되었다(Hawkins et al., 2001). 이상의 연구결과는 방어자 의 방어행동이 또래괴롭힘에 관여되어 있는 구성원들에게 다 양한 방식으로 영향을 줌으로써 괴롭힘을 중재할 수 있기 때 문에 방어행동을 보이는 요인을 탐색하고 이를 증진시키기 위 한 방안을 고안하는 것이 매우 중요한 과제임을 뒷받침하고 있다.

또래괴롭힘 방어행동에 영향을 주는 요인으로는 공감(Han $\& \mathrm{Oh}, 2014)$, 도덕적 이탈(Oberman, 2011), 문제중심 대처전 략(Pozzoli \& Gini, 2010) 등의 변인들이 제시된 바 있으나 방어 행동의 선행요인을 탐색하는 데 있어서 무엇보다 중요하게 고 려되어야 할 점은 아동이 또래괴롭힘에 개입하기 이전에 자신 이 어떤 행동을 수행할지를 결정해야 한다는 점이다. 즉, 또래 괴롭힘 상황을 목격한 아동은 피해자를 도와야 한다는 사실과 피해자를 도울 경우 자신이 가해자로부터 보복을 당할 수 있 으므로 개입하지 말아야 한다는 사실 간에 선택을 해야 하는 데(Salmivalli, 2010) 이 과정에서 또래괴롭힘을 목격한 아동이 피해자에 대한 도움이나 방어행동이 정말로 필요한 상황이라 고 인식하는 지가 어떤 선택을 하는지에 중요하게 작용한다. 예를 들어 피해아동이 가해를 받을 만한 상황이라고 인지하는 아동은 가해를 합리화하고 괴롭힘에 개입하지 않는 반면, 또 래괴롭힘이 무고한 아동이 해를 입는 부당한 상황이라고 인지 하는 아동은 적극적으로 피해자를 도울 수 있다.

이와 같은 의미에서 자신이 관찰한 상황을 어떻게 인식하 는지가 또래괴롭힘 상황에서 어떤 행동을 보일지를 결정하 는 데 영향을 줄 수 있으며 관련 요인으로 공정성에 대한 믿 음이 방어행동을 예측하는 요인으로 제시되고 있다(Correia, Kamble, \& Dalbert, 2009; Song, Son, \& Lee, 2018). 공정성에 대 한 믿음(beliefs in a just world)은 개인의 경험에 기초하여 자신 을 비롯한 집단 구성원들이 개인의 행동에 합당한 대우를 받 고 있다고 믿는 것을 의미한다(Dalbert, 1999; Lerner, 1980). 이 때 공정하다는 의미는 집단을 구성하는 구성원 간의 상호작 용에 의해 형성된 규칙에 따라 동일한 행동을 한 사람은 동일 한 결과를 제공 받는다는 것을 뜻한다(Lerner, 1980). 특히 초 등학교 아동에게 있어 공정한 상황은 발표 기회를 줄 때 친한 친구에게 우선권을 주는 것이 아니라 모두에게 동등하게 발 표의 기회가 주어지고 청소를 하면 보상을 준다는 규칙이 있 을 때 실제로 청소를 하면 보상을 주는 등의 상황을 포함한다 (Ministry of Education, 2019).

공정성에 대한 믿음은 7-8세 무렵부터 형성되기 시작하는 
데, 이 시기의 아동은 잘못된 행동은 무조건적인 처벌을 받는 다는 내재적 정의를 믿는다. 그러나 성장하면서 행동에 대한 결과는 무작위로 주어질 수 있다는 것을 깨닫게 되고 이와 같 은 무작위 결과를 이해하기 위해 공정성에 대한 믿음을 발달 시키게 된다(Dalbert, 2001). 이 때 아동이 경험하는 행동에 뒤 따르는 결과는 가정 내에서 아동과 아동의 형제자매에게 대 하는 부모의 태도 또는 아동이 속한 학급교사의 행동 등을 통 해 경험하는 결과들을 포함하며 부모와 교사가 공정하게 행 동하는 경우에 공정성에 대한 믿음은 더욱 강화된다(Dalbert $\&$ Stoeber, 2006). 이러한 공정성에 대한 믿음은 초등학교 고 학년 무렵 더욱 구체화되어 자신에 대한 집단의 공정한 대우 와 타인에 대한 집단의 공정한 대우와 관련된 믿음이 구분되 게 된다(Dalbert, 1999). 구분된 하위차원 중 자신에 대한 공정 성 믿음(belief in a just world for self)은 자신이 속한 집단 내에 서 자기 행동에 걸맞는 정당한 결과를 경험하고 있다고 믿는 것을 의미하며 타인에 대한 공정성 믿음(belief in a just world for others)은 집단 내 다른 구성원들이 그들의 행동에 합당한 대우를 받고 있다고 믿는 것을 뜻한다(Dalbert, 1999; Lipkus, Dalbert, \& Siegler, 1996). 이에 기초한 연구결과에 따르면 (Bègue, 2014; Sutton \& Winnard, 2007) 두 하위차원의 믿음은 특히 불공정한 상황에서 어떠한 행동을 취하게 되는지와 관련 하여 서로 다른 반응을 야기한다.

우선 자신에 대한 공정성 믿음은 친사회적 행동과 관련이 있는 것으로 제시되고 있다(Caroli \& Sagone, 2014). 예를 들어 Bègue (2014)의 연구에서 자신에 대한 공정성 믿음이 강한 개 인은 폭력 피해자들에 대한 지원을 더 많이 보이는 것으로 나 타났는데, 이는 자신이 속한 집단에서 스스로의 행동에 대해 정당한 결과를 받고 있다고 믿는 사람은 자신을 공정하게 대 우해주는 타인에게 자신도 공정하게 행동하는 것이 의미 있다 고 생각하기 때문이다(Strelan, 2007). 또래괴롭힘 상황에 이를 적용해보면 자신에 대한 공정성 믿음이 있는 아동은 부당하게 괴롭힘을 받는 피해아동이 존중받을 수 있도록 도와주는 것이 의미 있는 행동이라고 생각하게 되고 피해자를 보호하거나 가 해자의 가해 행동을 제지하는 방법 등을 통해 이 행동을 수행 할 수 있다. 또한 Cialdini, Baumann과 Kenrick (1981)이 제시한 부정적 상태 해소 모델(negative state relief model)에 따르면 개 인은 누군가가 피해를 입는 상황을 목격했을 때 죄책감, 슬픔 등의 부정적 상태를 경험하게 되며 피해자를 돕는 행동을 통 해 이를 해소할 수 있게 된다. 따라서 자신에 대한 공정성 믿음 수준이 높은 아동은 괴롭힘 피해아동을 무시하거나 돕지 않는 행동이 자신의 믿음에 반하는 행동이기 때문에 불편감을 더욱
크게 느끼게 되고 이를 해소하기 위해 피해자를 도울 수 있다. 반면 타인에 대한 공정성 믿음이 피해자에 대한 태도와 관 련을 살펴본 연구들은 다소 비일관적인 결과를 보여주고 있 다. 몇몇 연구자들은(Fox, Elder, Gater, \& Johnson, 2010) 타인 이 공정한 대우를 받고 있다는 믿음이 강할수록 피해자를 동 정하고 지지하는 행동을 더 많이 보인다고 보고하였으나, 일 부 연구 결과에서는(Furnham, 2003; Sutton \& Winnard, 2007) 타인이 행동에 대한 합당한 결과를 받고 있다고 믿을수록 피 해자를 비난하거나 도움행동이 감소하는 것으로 나타났다. 타 인에 대한 공정성 믿음이 피해자를 지지하는 행동과 관련되 는 것은 자신에 대한 공정성 믿음이 피해자를 돕는 행동에 영 향을 주는 과정과 유사하게 설명될 수 있다. 또래괴롭힘 피해 아동은 아무런 잘못을 하지 않았음에도 불구하고 가해를 받는 불공정한 상황에 처해있으며 이는 타인이 공정하게 대우받고 있다고 믿는 자신의 신념과 불일치하는 상항이기 때문에 이로 인한 불편감을 해소하기 위해 피해자를 적극적으로 도울 수 있다.

이와 다르게 타인에 대한 공정성 믿음이 피해자를 비난하 는 행동과 관련된다고 주장한 연구들은(Furnham, 2003) 상이 한 가정에 근거해 이를 설명한다. 이는 타인이 공정한 대우 를 받고 있다고 믿을수록 피해자가 받는 결과를 피해자의 잘 못으로 인해 받는 공정한 결과라고 판단함으로써 피해자를 비난하거나 그 상황을 합리화 할 수 있기 때문이다(Sutton \& Winnarrd, 2007). 예를 들어 Bègue와 Bastounis (2003)의 연구에 서는 타인에 대한 공정성 믿음이 강할수록 질병이나 가난 등 으로 어려움을 경험하는 사람들을 비난할 가능성이 높음을 보 여주었다. 이상과 같은 상충된 주장에도 불구하고 공정성에 대한 믿음과 방어행동과의 관계에 대한 연구는 제한적으로 이 루어졌다. 더구나 공정성에 대한 믿음과 방어행동과의 관계를 본 대부분의 선행연구에서 타인에 대한 공정성 믿음은 제외하 고 자신에 대한 공정성 믿음과 방어행동과의 관계만을 연구해 공정성에 대한 믿음이 또래괴롭힘 방어행동에 미치는 영향을 정확히 파악하는 데는 한계가 있었다. 따라서 공정성에 대한 믿음의 두 하위차원 모두를 포함하여 방어행동에 주는 영향이 다른지를 확인하는 것은 공정성에 대한 믿음과 방어행동 간의 관계에 대한 이해를 증진하는 데 도움이 될 수 있다.

한편, 공정성에 대한 믿음이 방어행동에 미치는 영향은 방 어자가 처한 맥락에 따라 달라질 수 있다. 특히 방어행동이 학 급 내에서 상대적으로 많은 권력을 갖고 있는 가해자에게 대응 하는 것이기 때문에 오히려 자신에게 위협이 가해질 수도 있다 는 사실은 방어자가 방어행동을 실제 실행에 옮기는 데에 중요 
하게 작용할 수 있다. 이러한 점에서 학급 내에서 가해행동에 대해 어떤 태도를 갖느냐에 따라 방어행동을 수행함에 따른 손 실이나 위험의 가능성이 커지거나 완화되고 이에 따라 방어행 동의 수준이 달라질 수 있다. 이와 같이 또래괴롭힘 허용여부 에 대한 학급 구성원들의 태도를 또래괴롭힘 허용분위기라고 하는데(S.-G. Lee, 1999) 구체적으로 또래괴롭힘 허용분위기란 학급 내에서 괴롭힘이 발생하는 것을 구성원들이 용인하고 동 조하는 정도라고 정의할 수 있으며 아동마다 학급 분위기는 다 르게 해석하고 지각할 수 있다(James \& Sells, 1981).

위에서 설명한 바와 같은 공정성에 대한 믿음, 방어행동, 학 급 내 또래괴롭힘 허용분위기의 관계는 각성: 비용-보상 모델 (arousal: cost-reward model)로 설명될 수 있다. 이 모델에 따르 면 위기 상황을 인식한 주변인은 도움을 제공할 때와 제공하 지 않을 때의 손실의 양을 비교하여 도움행동 여부를 결정하 게 되는데 손실이 적고 보상이 클 때 도움행동을 수행하게 된 다(Piliavin, Piliavin, \& Rodin, 1975). 이를 또래괴롭힘 상황에 적용해보면 공정성에 대한 믿음으로 인해 방어행동을 보이고 자 하는 아동이 자신의 학급이 가해행동을 용인한다고 지각한 다면 자신의 행동이 지지받지 못하고 손실이 더 커질 것을 예 상해 방어행동을 수행하지 않을 수 있다. 반대로 학급 내에서 발생하는 가해행동을 묵인하지 않고 피해자를 돕는 방어행동 을 지지하는 학급 분위기가 형성되어 있다고 지각하는 아동은 방어행동을 적극적으로 수행 할 가능성이 높아질 것이다. 아 직까지 이와 같은 학급분위기의 조절효과를 실제적으로 검증 한 연구는 없으나 또래괴롭힘 문제를 해결하기 위해서는 아동 개인에 대한 개입과 더불어 학교 환경과 같은 맥락적인 개입 이 같이 이루어져야 한다는 점에서(Ahn, 2016) 학급 내 또래괴 롭힘 허용분위기가 공정성에 대한 믿음과 또래괴롭힘 방어행 동의 관계를 조절하는지를 검증해보는 것이 필요하다.

학급 내 또래괴롭힘 허용분위기는 공정성에 대한 믿음이 방어행동에 미치는 영향을 조절할 뿐만 아니라 또래괴롭힘 방 어행동에 직접적인 영향도 줄 수 있다. 한 개인이 속한 집단의 가치와 개인의 행동은 서로 관계가 있으며 집단의 가치는 개 인의 행동 수행에 영향을 줄 수 있다는 점에서(Kristof, 1996) 가해행동에 대한 반감과 방어행동에 대한 지지를 중요한 가치 로 여기는 학급에서는 학급 구성원이 이 가치에 맞는 행동을 수행하며 방어행동이 증가될 수 있다. 실제로 선행연구에서 학급 구성원이 또래괴롭힘을 부정적으로 인식할수록 방어행 동을 더 많이 보이는 것으로 나타나 학급이 또래괴롭힘을 허 용하지 않는 분위기를 형성하고 있을 경우에는 방어행동이 더 많이 나타날 수 있음을 시사하였다(Shim \& Seo, 2013). 따라서
학급분위기가 어떤지에 따라 방어행동의 수준이 달라지는 지 를 검증하는 것은 학급 차원의 개입을 구성할 수 있다는 점에 서 필요하다.

이상의 필요성에 기초하여 본 연구에서는 초등학교 고학 년 아동의 공정성에 대한 믿음과 학급 내 또래괴롭힘 허용분 위기가 또래괴롭힘 방어행동에 미치는 영향을 검증하고 학 급 내 또래괴롭힘 허용분위기의 조절효과를 분석하고자 한 다. 이 때 남아보다 여아가 더 많은 방어행동을 보이고 학년이 높아질수록 방어행동이 감소하며, 또래괴롭힘 피해경험 수준 이 방어행동과 밀접한 관련이 있다는 선행연구결과(Pozzoli, Gini, \& Vieno, 2012; Salmivalli et al., 1996; Shon \& Lee, 2015) 에 기초하여 성과 학년, 또래괴롭힘 피해경험을 통제 변인으 로 포함하여 연구하고자 한다. 본 연구의 결과는 학급 내에서 발생하는 또래괴롭힘 상황에서 주변인의 행동을 이해하고 피 해자를 방어하도록 하는 요인을 파악함으로써 또래괴롭힘을 효과적으로 예방할 수 있는 방안을 마련하는 데 도움을 줄 수 있을 것이다.

이상의 연구 목적을 위해 본 연구에서 설정한 연구 문제는 다음과 같다.

\section{연구문제 1}

초등학교 고학년 아동의 공정성에 대한 믿음(자기, 타인)과 학급 내 또래괴롭힘 허용분위기는 또래괴롭힘 방어행동에 영향을 미 치는가?

\section{연구문제 2}

초등학교 고학년 아동의 공정성에 대한 믿음(자기, 타인)이 또래 괴롭힘 방어행동에 미치는 영향을 학급 내 또래괴롭힘 허용분위 기가 조절하는가?

\section{Methods}

\section{연구대상}

본 연구는 서울시, 경기도, 인천광역시에 위치한 11 개 초등학 교에 재학 중인 아동 중, 괴롭힘을 목격하거나 들은 적이 있는 4-6학년 학생 194명을 대상으로 하였으며 편의표집 방식으로 연구대상을 선정하였다. 연구대상 중 남학생이 95명(49.0\%), 여학생이 99명(51.0\%)으로 비슷한 분포를 보였으며 학년 별 
구성에 있어서는 4학년이 43명(22.2\%), 5학년이 63명(32.5\%), 6학년이 88명(45.4\%)으로 나타났다.

\section{연구도구}

\section{또래괴롭힘 방어행동}

초등학생의 또래괴롭힘 방어행동을 측정하기 위해 Salmivalli 등(1996)이 개발하고 Seo (2008)가 번안한 또래괴롭힘 참여자 역할 척도를 사용하였다. 본 연구에서는 Seo (2008)가 구분한 5 가지의 또래괴롭힘 참여자 역할 중 방어자의 방어행동을 측 정하는 6 개 문항만을 사용하였다. 각 문항은 전혀 그렇지 않았 다(1점)부터 항상 그랬다(5점)까지 5점 척도로 평정하도록 되 어있으며 문항의 예로는 "괴롭힘 당하는 아이에게 힘과 용기를 주었다." 등이 있다. 가능한 점수의 범위는 6점에서 30점이며 점수가 높을수록 또래괴롭힘 상황에서 피해자를 도와주거나 가해자의 가해 행동을 제지하는 행동을 많이 보였다는 것을 의미한다. 본 연구에서 산출한 내적합치도 계수 Cronbach's $\alpha$ 는 .87이었다.

\section{공정성에 대한 믿음}

초등학생의 공정성에 대한 믿음을 측정하기 위해 Dalbert (1999) 가 개발하고 Jung과 Ahn (2017)이 번안한 척도를 사용하였다. 하위차원인 자신에 대한 공정성 믿음 6 개 문항, 타인에 대한 공 정성 믿음 5 개 문항으로 구성되어 있으며 중·고등학생 대상 척 도이기 때문에 예비조사 결과를 토대로 초등학교 고학년 아동 이 이해할 수 있도록 쉬운 단어로 수정하거나 문항 길이를 축 소하여 사용하였다. 각 문항은 전혀 그렇지 않다(1점)부터 매 우 그렇다(6점)까지의 6점 척도로 평정하도록 되어있으며 가 능한 점수 범위는 자신에 대한 공정성 믿음이 6점에서 36점, 타 인에 대한 공정성 믿음이 5점에서 30점이다. 자신에 대한 공정 성 믿음의 문항 예시로는 "내가 경험하는 일들은 대부분 공정 하다.” 등이 있으며 타인에 대한 공정성 믿음의 문항 예시로는 "세상은 정의로운 곳이다." 등이 있다. 자신에 대한 공정성 믿 음점수가 높을수록 내가 수행한 행동에 대해 정당한 결과를 받 고 있다고 강하게 믿으며 타인에 대한 공정성 믿음점수가 높을 수록 나를 제외한 타인이 행동에 대해 합당한 대우를 받고 있 다는 믿음수준이 높은 것을 의미한다. 본 연구에서 산출된 내 적합치도 계수 Cronbach's $\alpha$ 는 두 하위차원 모두 .78이었다.

\section{학급 내 또래괴롭힘 허용분위기}

초등학교 고학년 아동이 지각하는 학급 내 또래괴롭힘 허용분 위기는 Rigby와 Slee (1991)의 또래괴롭힘 척도와 S.-G. Lee (1999) 의 학교폭력 허용에 관한 문항을 참고하여 M. Park (2000)이 구성한 척도를 사용하였다. 총 7 개 문항으로 구성되어 있으며 4점 척도로 측정하는 원척도의 신뢰도가 다소 낮게 나타나 척 도의 신뢰도를 높이기 위해서는 중간 반응을 측정하여 평균 을 다양화하고 5점 척도 이상이 권장된다는 Jahng (2015)의 연구 에 기초해 본 연구자가 전혀 그렇지 않다(1점)부터 매우 그렇다 (5점)까지의 5점 척도로 평정하도록 수정하여 사용하였다. 문 항의 예시로는 "우리 반 친구들은 괴롭힘 당하는 것을 볼 때 모른 척 한다.” 등이 있으며 5, 6, 7번 문항을 역채점하여 가능 한 총점은 7점에서 35점이다. 점수가 높을수록 학급 내에서 가해행동을 용인하고 이를 지지하는 분위기가 형성되어 있음 을 의미하며 본 연구에서 산출한 내적합치도 계수 Cronbach's $\alpha$ 는.68이었다.

\section{또래괴롭힘 피해경험}

통제변인으로 포함된 또래괴롭힘 피해경험을 측정하기 위해 J.-Y. Lim (1997)이 번안한 Grotpeter와 Crick (1996)의 사회적 경험 질문지를 사용하였다. 원척도는 15 개 문항으로 구성되 어 있으나, 본 연구에서는 그 중 괴롭힘 경험을 측정하는 10 개 문항만을 사용하였으며 문항 예시로 "다른 친구들이 나를 싫 어하게 하려고 나에 대해 거짓말하는 친구가 있었다.", “친구 들이 나를 때린 적이 있다.” 등이 있다. 본 척도는 5점 척도로 서 전혀 그렇지 않다(1점)에서 항상 그렇다(5점)으로 평정하 게 되어있다. 가능한 총점 범위는 10 점에서 50 점까지로 점수 가 높을수록 또래로부터 의도적인 신체적 또는 언어적 괴롭힘 을 받았거나 사회적 관계를 손상시키는 행동을 경험한 적이 많다는 것을 의미한다. 본 연구에서 산출한 내적합치도 계수 Cronbach's $\alpha$ 는 .85이었다.

\section{연구절차}

본 조사는 2019년 9월 중에 연구자가 임의로 선정한 서울, 경 기, 인천 지역 소재의 11 개 초등학교에서 실시되었다. 참여에 동의한 초등학생을 대상으로 질문지를 배부하고 자기보고식 으로 응답한 질문지를 회수하는 방식으로 조사를 진행하였다. 총 760 부의 질문지를 배부하였으며 그 중 690 부를 회수하였 
Table 1

Means and Standard Deviations of the Variables

\begin{tabular}{lcccc}
\hline \multicolumn{1}{c}{ Variables } & Possible score range & $M(S D)$ & Item score range & $M(S D)$ \\
\hline Victimization & $5-50$ & $17.92(6.81)$ & $1-5$ & $1.80(.69)$ \\
Defending behavior & $6-30$ & $16.93(5.74)$ & $1-5$ & $2.83(.96)$ \\
Belief in a just world (BJW) & & & & \\
$\quad$ BJW for self & $6-36$ & $24.66(4.77)$ & $1-6$ & $4.12(.78)$ \\
$\quad$ BJW for others & $5-30$ & $19.61(5.13)$ & $1-6$ & $3.93(1.02)$ \\
Bullying acceptance & $7-35$ & $15.56(4.39)$ & $1-5$ & $2.23(2.14)$ \\
\hline
\end{tabular}

Note. $N=194$.

고, 회수율은 약 $91 \%$ 였다. 회수한 질문지 중 실제 또래괴롭힘 을 목격하거나 들은 경험이 있다고 응답한 201명의 아동만을 분석 대상으로 하였으며 이 중 두 개 이상의 척도에서 동일번 호에 일괄적으로 응답하거나 한 척도 이상 응답이 누락된 자 료 또는 결측치가 발생한 자료를 제외한 194 명을 최종 분석에 사용하였다. 응답 중 발생한 결측치는 평균대치법으로 처리하 였다.

\section{자료분석}

수집된 자료는 SPSS 25.0 (IBM Co., Armonk, NY)프로그램과 Mplus version 8.0 (Muthén \& Muthén, Los Angeles, CA) 프로그 램을 사용하여 다음과 같은 절차를 통해 분석하였다. 첫째, 연 구 대상의 사회인구학적 특성과 연구변인들의 일반적 경향을 알아보기 위하여 기술통계치를 산출하였다. 둘째, 공정성에 대한 믿음과 또래괴롭힘 허용분위기가 또래괴롭힘 방어행동 에 미치는 영향과 공정성에 대한 믿음과 방어행동 간의 관계 를 또래괴롭힘 허용분위기가 조절하는지를 확인하기 위하여 성별, 학년, 또래괴롭힘 피해경험을 통제변인으로 위계적 회 귀분석을 실시하였다. 셋째, 조절효과에 대한 추가검증을 위 해 존슨-네이만 기법(Johnson-Neyman technique [J-N])에 의한 신뢰밴드(confidence band)를 산출하였다. 조절효과의 추가적 인 검증은 단순기울기 검증이 많이 사용되었으나 이는 연구자 가 임의로 상하집단을 구분한다는 점에서 제한점을 가지고 있 어 최근에는 실제로 유의한 차이가 나는 집단 구분에 따른 조 절효과를 나타내주는 J-N기법이 활용되고 있다(Hayes, 2013).

\section{Results}

\section{연구변인의 일반적 경향}

본 연구에서 측정한 초등학교 고학년 아동의 또래괴롭힘 방어 행동, 공정성에 대한 믿음, 학급 내 또래괴롭힘 허용분위기의 가능한 점수 범위와 실제 점수범위, 평균 및 표준편차는 Table 1 에 제시된 바와 같다.

먼저 초등학교 고학년 아동의 또래괴롭힘 피해경험의 문항 평균 점수는 1.80 점이었으며 이는 1 점의 전혀 그렇지 않다와 2 점의 거의 아니다의 중간에 해당하는 값으로 본 연구에 참여한 초등학교 고학년 아동의 또래괴롭힘 피해경험 수준은 매우 낮 은 편임을 알 수 있다. 이어서 초등학교 고학년 아동의 또래괴롭 힘 방어행동의 문항 평균 점수는 2.83 점이었다. 이는 2 점의 가끔 그랬다와 3점의 보통 그랬다의 중간에 해당하는 값으로 본 연 구에 참여한 초등학교 고학년 아동의 방어행동 수준은 다소 낮 은 편임을 보여주었다. 다음으로 초등학교 고학년 아동의 공정 성에 대한 믿음의 문항 평균을 하위차원 별로 살펴보면 자신에 대한 공정성 믿음이 4.12점, 타인에 대한 공정성 믿음이 3.93점 이었다. 자신에 대한 공정성 믿음의 점수는 4점의 그런 편이다 와 5점의 대체로 그렇다의 중간점수로 연구 대상의 자신이 공정 하게 대우받고 있다고 믿는 수준은 다소 높은 편이며, 타인에 대 한 공정성 믿음 점수는 3점의 그렇지 않은 편이다와 4점의 그런 편이다의 중간에 해당하는 값으로 보통 수준의 믿음을 갖고 있 는 것으로 나타났다. 마지막으로 초등학교 고학년 아동의 학급 내 또래괴롭힘 허용분위기 문항 평균 점수는 2.23점으로 나타났 다. 이는 2점의 대체로 그렇지 않다와 3점의 보통이다의 중간에 해당하는 값으로 연구에 참여한 초등학생들의 학급에서 대체 로 또래괴롭힘을 허용하지 않는 분위기에 가까움을 의미한다. 
Table 2

Correlation Coefficients Among the Variables

\begin{tabular}{|c|c|c|c|c|c|c|c|}
\hline Variables & 1 & 2 & 3 & 4 & $5-1$ & $5-2$ & 6 \\
\hline 2. Grade & -.03 & - & & & & & \\
\hline 3. Victimization & -.01 & -.14 & - & & & & \\
\hline 4. Defending behavior & .03 & .05 & .12 & - & & & \\
\hline 5-1. BJW for self & -.02 & .02 & $-.42^{* *}$ & $.22^{* *}$ & - & & \\
\hline 5-2. BJW for others & -.12 & -.09 & $-.17^{*}$ & $.29^{* *}$ & $.58^{* *}$ & - & \\
\hline 6. Classroom climate & -.01 & -.05 & $.29^{*}$ & $-.22^{* *}$ & $-.33^{* *}$ & $-.21^{* *}$ & - \\
\hline
\end{tabular}

Note. $N=194$. BJW = belief in a just world.

${ }^{*} p<.05 .{ }^{* *} p<.01$.

\section{초등학교 고학년 아동의 공정성에 대한 믿음 과 학급 내 또래괴롭힘 허용분위기가 또래괴 롭힘 방어행동에 미치는 영향과 또래괴롭힘 허용분위기의 조절효과}

초등학교 고학년 아동의 공정성에 대한 믿음의 하위차원과 학 급 내 또래괴롭힘 허용분위기가 또래괴롭힘 방어행동에 미치 는 영향을 검증하기 위하여 먼저 측정 변인들 간의 상관관계 를 알아보고자 Pearson의 적률상관계수를 산출하였다. 분석 결 과는 Table 2 와 같다.

이후 초등학교 고학년 아동의 공정성에 대한 믿음과 학급 내 또래괴롭힘 허용분위기가 또래괴롭힘 방어행동에 미치는 영향을 알아보기 위해 또래괴롭힘 방어행동을 종속변인으로 한 위계적 중다회귀분석을 실시하였다. 1 단계에서는 성, 학년, 또래괴롭힘 피해경험을 통제변인으로 투입하였으며 2단계에 서는 자신에 대한 공정성 믿음, 타인에 대한 공정성 믿음과 학 급 내 또래괴롭힘 허용분위기를 독립변인으로 투입하였다. 또 한 초등학교 고학년 아동의 공정성에 대한 믿음이 또래괴롭힘 방어행동에 미치는 영향을 학급 내 또래괴롭힘 허용분위기가 조절하는지를 확인하기 위해 마지막 3단계에서 공정성에 대한 믿음의 하위차원과 학급 내 또래괴롭힘 허용분위기의 상호작 용항을 투입하여 회귀분석을 실시하였다. 분석결과는 Table 3에 제시된 바와 같다.

통계분석 결과, 1 단계에 투입된 통제변인 중 성과 학년의 영 향은 유의하지 않았으나 또래괴롭힘 피해경험 $(\beta=.27, p<.001)$ 은 또래괴롭힘 방어행동을 유의하게 예측하는 것으로 나타났 다. 이러한 결과는 또래괴롭힘 피해경험이 많을수록 또래괴롭
힘 방어행동을 더 많이 보이는 경향이 있음을 의미한다. 2 단계 에서 투입된 변인 중 타인에 대한 공정성 믿음 $(\beta=.21, p<.05)$ 과 학급 내 또래괴롭힘 허용분위기 $(\beta=-.22, p<.01)$ 는 또래괴 롭힘 방어행동에 각각 유의한 정적 영향과 부적 영향을 미치는 것으로 나타났다. 구체적으로 타인에 대한 공정성 믿음수준이 높을수록, 학급 내에서 또래괴롭힘을 허용하지 않을수록 또래 괴롭힘 방어행동을 할 가능성이 높음을 의미한다. 반면 자신에 대한 공정성 믿음이 또래괴롭힘 방어행동에 미치는 영향은 유 의하지 않았다. 마지막으로 3 단계에서 공정성에 대한 믿음의 하위차원과 학급 내 또래괴롭힘 상호작용항 중 자신에 대한 공 정성 믿음과 학급 내 또래괴롭힘 상호작용항만이 통계적으로 유의한 것으로 나타났다 $(\beta=-.20, p<.05)$. 이는 자신에 대한 공 정성 믿음이 또래괴롭힘 방어행동에 미치는 영향이 학급 내 또 래괴롭힘 허용분위기에 따라 달라진다는 것을 의미한다. 1 단 계에 투입된 변인은 $1 \%, 2$ 단계에 투입된 변인이 추가로 $16 \%$ 를 설명하였고, 3 단계에 투입된 변인의 설명량이 $3 \%$ 로 투입된 변 인들은 종속변인 총 변량의 $20 \%$ 를 설명하였다.

구체적으로 자신에 대한 공정성 믿음과 또래괴롭힘 방어행 동의 관계에 대해 학급 내 또래괴롭힘 허용분위기의 어느 영 역이 조절효과를 보이는지 알아보기 위하여 J-N기법에 의한 신뢰밴드를 통해 조건부효과의 유의한 영역을 확인하였다. 그 결과 평균중심화한 학급 내 또래괴롭힘 허용분위기의 점수가 -.96 (상위 $58.76 \%$, 하위 $41.24 \%$ ) 이하인 지점 $(n=80)$ 부터 자 신에 대한 공정성 믿음과 또래괴롭힘 방어행동 간의 관계에 유의한 영향을 미치는 것으로 나타났다. 이는 학급 내에서 또 래괴롭힘 허용분위기의 수준이 높은 영역보다 낮은 영역에서 자신에 대한 공정성 믿음으로 인한 또래괴롭힘 방어행동이 나 
Table 3

Hierarchical Regression Analysis: The Effects of Beliefs in a just World and Classroom Climate Regarding Bullying on Defending Behavior Against Bullying and Moderating Effect of Classroom Climate

\begin{tabular}{|c|c|c|c|}
\hline Variables & Step 1 & Step 2 & Step 3 \\
\hline Gender $^{\mathrm{a}}$ & -.02 & -.04 & -.02 \\
\hline Grade & -.03 & -.01 & -.01 \\
\hline Victimization & -.11 & $.27^{* * *}$ & $.27^{* * *}$ \\
\hline \multicolumn{4}{|l|}{ BJW } \\
\hline BJW for self $(A)$ & & .14 & .15 \\
\hline BJW for other (B) & & $.23^{* *}$ & $.21^{*}$ \\
\hline Bullying acceptance (C) & & $-.21^{* *}$ & $-.22^{* *}$ \\
\hline$A \times B$ & & & $-.20^{*}$ \\
\hline $\mathrm{A} \times \mathrm{C}$ & & & -.06 \\
\hline$R^{2}$ & .01 & $.17^{* * *}$ & $.20^{*}$ \\
\hline$\Delta R^{2}$ & & $.16^{* * *}$ & $.03^{*}$ \\
\hline$F$ & .88 & $6.67^{* * *}$ & $5.94^{* * *}$ \\
\hline
\end{tabular}

Note. $N=194$. BJW = belief in a just world.

${ }^{\mathrm{a}}$ male $=1 ;$ female $=0$.

${ }^{*} p<.05 .{ }^{* *} p<.01 .{ }^{* * *} p<.001$.

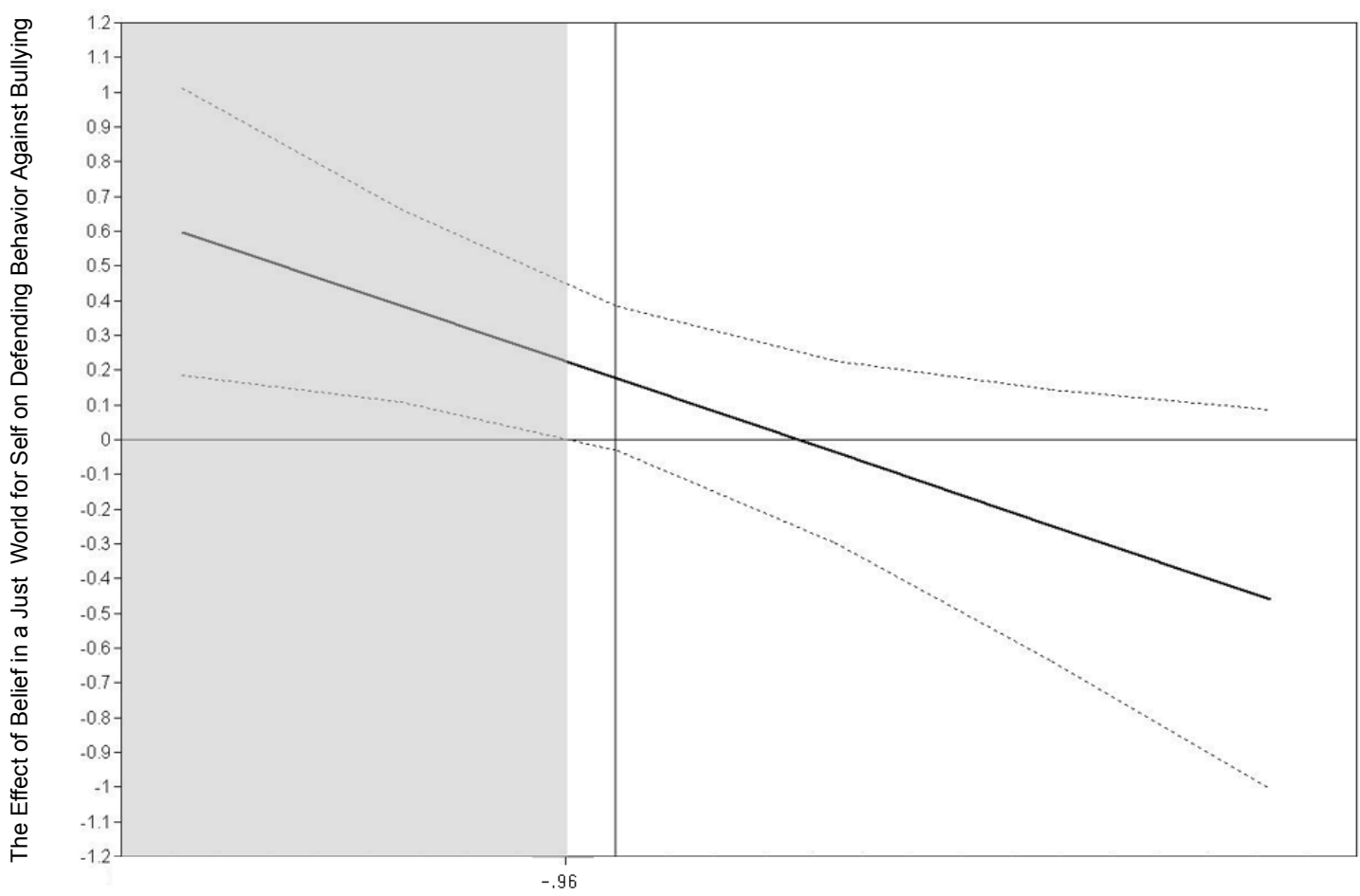

Classroom Climate Regarding Bullying

Figure 1. Moderating effects of classroom climate regarding bullying on the relationship between belief in a just world for self and defending behavior. 
타날 가능성이 높다는 것을 나타낸다. 이에 대한 결과는 Figure 1 에 제시된 바와 같다.

Figure 1에서 종축은 독립변인이 종속변인에 미치는 영향 으로써 자신에 대한 공정성 믿음이 또래괴롭힘 방어행동에 미 치는 영향력을 의미하며, 횡축의 경우 조절변인인 또래괴롭힘 허용분위기의 평균중심화 된 값을 나타낸다. 그래프의 점선들 은 $95 \%$ 구간 내 유의성 영역을 나타내며, 해당 영역 내 직선은 학급 내 또래괴롭힘 허용분위기 수준의 변화에 따라 자신에 대한 공정성 믿음이 또래괴롭힘 방어행동에 미치는 영향력이 어떻게 달라지는가를 나타내는 회귀선이다. 그래프의 회색영 역은 학급 내 또래괴롭힘 허용분위기 수준에 의해 자신에 대 한 공정성 믿음이 또래괴롭힘 방어행동에 미치는 영향력이 달 라지는 유의한 영역을 의미한다. 즉 하단 부의 점선과 종축이 0 일 때의 값과 만나는 지점 이하부터 학급 내 또래괴롭힘 허용 분위기의 조절효과가 유의함을 알 수 있다. 이 때 종축의 값이 0 이라는 것은 학급 내 또래괴롭힘 허용분위기 수준에 의해 자 신에 대한 공정성 믿음이 또래괴롭힘 방어행동에 미치는 영향 력의 변화가 없음을 뜻하기 때문에 점선의 종축이 0 일 때의 학 급 내 또래괴롭힘 허용분위기 $(\mathrm{X}=-.96)$ 이하부터 자신에 대한 공정성 믿음이 또래괴롭힘 방어행동에 미치는 영향을 유의하 게 조절할 수 있음을 보여준다.

\section{Discussion}

본 연구는 초등학교 고학년 아동을 대상으로 공정성에 대한 믿음, 학급 내 또래괴롭힘 허용분위기가 또래괴롭힘 방어행동 에 미치는 영향을 알아보고 공정성에 대한 믿음과 방어행동과 의 관계에 대한 학급 내 또래괴롭힘 허용분위기의 조절효과를 검증하였다. 본 연구를 통해 나타난 주요 결과들을 논의하고 결과에 따른 시사점을 서술하면 다음과 같다.

연구문제 1 과 관련하여 초등학교 고학년 아동의 공정성에 대한 믿음과 학급 내 또래괴롭힘 허용분위기가 또래괴롭힘 방 어행동에 미치는 영향을 살펴보기 위해 성, 학년, 또래괴롭힘 피해경험을 통제변인으로 포함하여 분석한 결과 공정성에 대 한 믿음의 하위차원 중 타인에 대한 공정성 믿음과 또래괴롭 힘 허용분위기는 방어행동에 유의한 영향을 미치는 것으로 나 타났다. 구체적으로 타인에 대한 공정성 믿음수준이 높을수 록, 학급 내에서 또래괴롭힘을 허용하지 않을수록 또래괴롭힘 방어행동을 많이 보이는 경향이 있었다.

우선 타인에 대한 공정성 믿음이 방어행동에 유의한 정적
영향을 준 결과는 타인이 공정하게 대우받고 있다고 믿을수록 피해자를 동정하고 지지하는 행동을 보였다는 선행연구 결과 와 맥을 같이한다(Fox et al., 2010). 타인에 대한 공정성 믿음이 피해자를 비난하는 행동이 아니라 피해자를 돕는 행동과 정적 상관이 있는 것으로 나타난 결과는 또래괴롭힘 피해자가 자신 이 속한 학급 구성원이라는 점을 고려해 해석할 수 있다. 타인 에 대한 공정성 믿음이 피해자에 대한 비난 등과 관련되는 것 으로 보고 한 연구결과들은(Bègue \& Bastounis, 2003; Sutton \& Winnard, 2007) 피해자에 대한 정보가 제한적으로 제공되고 질병 등의 부정적인 결과를 받게 된 책임여부를 제시하지 않은 상황에서 피해자에 대한 태도를 측정한 것이었다. 그러나 또 래괴롭힘 피해자는 자신과 함께 생활하고 있는 학급의 구성원 이기 때문에 피해자에 대한 정보를 충분히 알 수 있고 피해자 가 가해를 받게 되는 이유를 확인할 수 있다. 따라서 괴롭힘을 목격한 아동은 타인이 명백하게 부당한 대우를 받고 있다는 것을 인식할 수 있고, 타인이 공정하게 대우 받고 있다고 믿는 자신의 믿음에 반하는 상황에서 발생하는 부정적 감정을 해소 하기 위해 적극적으로 피해자를 돕고자 하는 것으로 이해할 수 있다. 본 연구의 결과는 공정성에 대한 믿음을 높여주는 것 이 또래괴롭힘 상황에서 적극적으로 피해자를 돕도록 하는 데 도움이 될 수 있음을 의미한다.

공정성에 대한 믿음이 최초로 발달하는 맥락이 가정이며 가정에서 공정한 결과를 경험하는 것이 이 믿음의 발달을 촉 진할 수 있다는 주장에 기초해 볼 때(Dalbert, 2001) 부모가 아 동이 보이는 행동에 어떻게 반응하느냐에 따라 아동의 공정성 에 대한 믿음 수준은 달라질 수 있다. 아동에게 있어 공정함이 라는 의미가 정해진 규칙에 따른 결과를 받고, 외적인 요인에 관계없이 실제 내가 수행한 행동에 따른 상과 벌을 받는 것이 라는 점을 감안한다면(Ministry of Education, 2019) 부모가 형 제, 자매 간 갈등에서 한 쪽의 편만 드는 것이 아니라 실제 잘 못한 행동에 대해서 적절한 처벌과 보상을 제공하고 정해진 가족규칙을 일관적으로 적용하는 것이 가정 내에서 아동을 공 정하게 대하는 예시가 될 수 있다. 공정한 분위기가 형성되어 있는 가정에서 공정성에 대한 믿음의 두 하위차원 모두가 향 상되었다는 연구결과는(Sallay \& Dalbert, 2004) 부모가 공정한 결과를 지속적으로 제공하는 것이 아동의 공정성에 대한 믿음 을 향상시킴으로써 또래괴롭힘을 목격했을 때 방어행동을 더 많이 보이도록 하는 효과적인 방법이 될 수 있음을 보여준다.

가정에서의 경험뿐만 아니라 학교에서 보내는 시간이 많아 지는 초등학교 아동에게 학급 구성원 모두가 공정한 대우를 받고 이를 목격하는 경험도 공정성에 대한 믿음 발달에 영향 
을 줄 수 있다. 예를 들어 교사가 학기가 시작되기 이전에 학급 구성원과 함께 학급 모두에게 해당하는 규칙을 설정하고 학교 생활 전반에 있어 동일한 행동에 대해 일관성 있는 행동의 결 과를 경험하게 한다면 아동의 공정성에 대한 믿음 수준이 높 아지면서 괴롭힘 상황에서 방어행동을 더 많이 하도록 하는 효과를 거둘 수 있다. 실제로 교사로부터 공정한 대우를 받고 있다고 지각하는 아동은 공정성에 대한 믿음이 높은 것으로 나타난 연구결과가(Donat, Umlauft, Dalbert, \& Kamble, 2012) 이를 뒷받침 한다.

그러나 타인에 대한 공정성 믿음을 가지고 있다고 하더라 도 부정적 결과를 받는 타인의 입장을 인지하지 못하거나 이 해할 수 없는 경우에는 불공정한 결과를 정당화할 수 있다는 점에서(Kogut, 2011) 단순히 믿음수준을 높이는 것은 도움행 동으로 연결되지 않을 수도 있다. 따라서 다른 사람의 입장을 이해하고 타인의 관점에서 생각해 볼 수 있도록 돕는 활동은 타인에 대한 공정성 믿음이 긍정적인 방향으로 작용할 수 있 도록 하는 데 도움이 될 수 있다. 이와 관련하여 Yang, Kim과 Lee (2009)는 학교폭력 예방을 위한 배려증진 프로그램을 개 발한 바 있는데 이 프로그램은 아동의 조망수용 능력, 공감 능 력 등을 증진하고 이를 바탕으로 학급 구성원들에게 도움을 줄 수 있도록 하는 것을 목표로 한다. 프로그램의 시행 후에 아 동의 공감능력이 향상되었고 이를 바탕으로 친구들을 돕는 행 동이 증가했다는 결과는 이러한 프로그램이 아동으로 하여금 부당한 결과를 받는 타인의 입장에서 생각해 볼 수 있도록 함 으로써 타인에 대한 공정성 믿음이 피해자를 돕는 행동으로 이어질 수 있도록 하는 데에 도움이 될 수 있음을 시사한다.

반면 자신에 대한 공정성 믿음이 방어행동을 촉진한다는 선행연구자들의 주장(Correia et al., 2009; Song et al., 2018)과 달리, 본 연구에서는 직접적인 영향이 나타나지 않았다. 이는 개인이 맥락에 관계없이 자신이 공정하게 행동하고 공정한 결 과를 받는다고 믿고 있기 때문에(Messick, Bloom, Boldizar, \& Samuelson, 1985) 방어행동에 대한 영향이 직접적이지 않았을 수 있다. 그러나 조절효과를 고려했을 때 조건부적인 효과를 보여 해석에 유의할 필요가 있다. 이와 관련하여서는 조절효 과와 관련된 서술에서 구체적으로 논의하였다.

한편 학급분위기의 경우 학급 내에서 괴롭힘을 허용하지 않을수록 또래괴롭힘 방어행동을 더 많이 보이는 것으로 나타 나 선행연구자들(Pozzoli et al., 2012; Song \& Lee, 2018)의 주장 을 지지하였으며, 이는 다음과 같이 해석해 볼 수 있다. 집단이 공유하는 가치는 개인의 행동과 서로 연관되어 있으며 집단의 가치는 개인의 행동에 영향을 미친다. 또한 집단이 추구하는
가치에 부응하는 행동을 할 때 개인은 만족감을 느끼며 그렇 지 않은 상황에서는 불편감을 느끼고 집단의 구성원과 의사소 통하는 데 어려움을 느낀다(Kristof, 1996). 따라서 학교 내에서 또래와의 관계가 중요해지는 초등학교 시기의 아동은 학급 내 에서 가해행동을 지지하지 않고 피해자를 도와야 한다는 분위 기가 형성되어 있다고 지각하는 경우에 집단에 소속되기 위해 그 분위기에 맞추어 행동할 수 있다. 예를 들어 자신이 속한 학 급에서 가해행동이 용인되지 않는다고 지각하는 아동은 괴롭 힘이 발생했을 때 가해행동을 비난하거나 적극적으로 말리는 반응을 보일 수 있으며, 혹은 교사에게 알려 도움을 청하거나 피해자를 위로하는 등 다양한 방식으로 피해자를 보호하고 돕 는 행동을 하게 된다. 이와 같은 의미에서 본 연구결과는 학급 내에 괴롭힘을 허용하지 않는 분위기를 형성하는 것이 아동이 이러한 분위기를 인식하도록 도와 방어행동을 증가시키고, 궁 극적으로는 또래괴롭힘 발생을 감소시키는 데에 도움이 될 수 있음을 보여주고 있다.

또래괴롭힘 가해행동을 용인하지 않는 분위기를 조성하 기 위해서는 가해행동이 옳지 않은 행동이라고 알려주는 프 로그램들을 확장-적용해보는 것이 도움이 될 수 있다. 이와 관련하여 몇몇 프로그램들이 개발된 바 있는데 예를 들어 '학 교폭력 멈춰(Moon et al., 2012)'는 노르웨이의 Olweus bullying prevention program을 국내 실정에 맞게 수정한 프로그램으로서 괴롭힘 문제의 감소, 학교폭력 예방 및 안정된 학급문화 형성에 초점을 둔다. 이 프로그램은 괴롭힘이 발생했을 때 피해자 또는 이를 목격한 아동이 ‘멈춰’라고 말하면 학급회의를 소집해 역 할극을 수행함으로써 서로의 입장을 이해할 수 있도록 한다. 또한 예방차원에서 괴롭힘이 발생하지 않더라도 역할극을 통 해 주변인으로서 어떻게 행동해야 하는지를 배울 수 있다. 이 프로그램은 아동들이 괴롭힘 상황에서 쉽게 가해행동에 개입 할 수 있다는 장점이 있으나 괴롭힘이 발생했을 때 교사가 실제 적으로 개입해 진행하는 교사의 학급회의 진행이 필요하다. 따라서 교사의 개입이 불가능한 상황에서의 괴롭힘에 대해서 는 ‘멈춰'라는 개입이 일어나지 않을 가능성이 높다는 제한점 을 가진다. 이상에 기초해보았을 때 현재 사용되는 프로그램 들은 피해자의 입장을 이해할 수 있도록 하는 교육을 통해 아 동의 공감 수준을 높여 가해행동이 발생했을 때 이를 제지하는 분위기를 형성하는 데 도움을 주고자 하고 있다.

그러나 기존의 프로그램들은 다소 피상적인 교육에 그칠 수 있으며 실제 피해자가 느끼는 감정을 느끼기에는 역부족 일 것으로 보인다. 이를 보완하기 위한 방법으로 보다 더 실제 인 것처럼 체험할 수 있도록 하는 가상현실 프로그램(virtual 
reality program)이 피해자의 입장을 이해하고 공감하는 데 효 과적으로 적용될 수 있다. 미국의 Harmony Labs (2015)가 개발 한 ‘Stand up' 프로그램은 이러한 가상현실을 활용하여 또래괴 롭힘을 목격한 아동이 이를 해결하기 위해 적극적으로 개입하 도록 변화시키는 데 목적을 둔 프로그램이다. 이 프로그램은 가상현실 기술을 통해 피해자의 입장에서 가해를 받는 상황 을 경험하고, 이를 목격한 주변의 아동이 어떤 행동을 했을 경 우에 괴롭힘 상황이 중지되는 지를 확인해보도록 구성되어 있 다. 이러한 가상현실 프로그램은 실제 괴롭힘 피해를 받지 않 더라도 현실과 비슷한 수준의 괴롭힘 상황을 경험해볼 수 있 기 때문에 주변인으로 하여금 피해자에게 더 공감하도록 하고 실제 괴롭힘이 발생했을 때 적극적으로 개입하도록 할 수 있 다. 실제로 Ingram 등(2019)의 연구에서 위 프로그램의 효과를 분석한 결과, 프로그램에 참여한 아동들의 가해행동 참여 빈 도가 감소하였으며 피해자에 대한 공감 수준과 또래괴롭힘 상 황에 개입하고자 하는 의지도 향상되었음을 발견하였다. 따라 서 가상현실 프로그램을 국내 실정에 맞게 개발하여 제공하는 것은 또래괴롭힘 가해행동을 줄이고 주변인을 괴롭힘 상황에 적극적으로 개입하도록 만드는 데 도움이 될 수 있다.

더불어 최근 또래괴롭힘은 초등학교 뿐 아니라 중고등학교 에서도 지속적으로 나타나고 있으며 특히 중학교에서 월등하 게 많이 나타나고 있다(Ministry of Education, 2018). 그럼에도 불구하고 청소년을 대상으로 많이 시행되고 있는 학교폭력 예 방 프로그램인 어울림 프로그램(H. Park, Han, \& Kim, 2016) 역시 초등학생을 대상으로 한 프로그램들과 마찬가지로 피해 아동의 입장을 이해하기 위한 방법으로 역할극을 주로 사용하 고 있어 제한적인 부분이 있다. 이를 고려했을 때 가상현실 프 로그램을 중고등학교로 확대 운용하는 것은 초등학교 때부터 반복적이고 일관적인 교육을 가능하게 함으로써 가해 행동이 옳지 않고 피해자를 도와야 한다는 사실을 보다 명확하게 전 달하는 데 효과적일 수 있다. 또한 신체적, 인지적 성장에 따라 각 학년에서 나타날 수 있는 괴롭힘의 유형이 차이가 있을 수 있다는 점에서 학급회의 등을 통해 학생들이 직접 경험하거나 목격한 괴롭힘 상황을 프로그램의 내용으로 채택해 사용하는 것은 각 학급 상황에 맞는 개별적인 프로그램 제공이 가능해 짐으로써 피해자의 입장을 보다 더 잘 이해하도록 하는 데 도 움이 될 수 있다.

이와 같이 학생들을 대상으로 하는 프로그램과 더불어 교 사에 대한 직접적인 교육 또한 필요하다. 교사가 학급 분위기 형성에 영향을 미칠 뿐만 아니라 평소에 괴롭힘 상황이 발생 하는지에 대한 지도나 감독을 하고 있다고 지각할수록 학생들
의 방어행동이 증가된다는 점을 고려했을 때(Farmer, Lines, \& Hamm, 2011; Shim \& Seo, 2013) Kim (2019)이 제시한 바와 같 이 학교폭력에 대한 교사의 민감성을 증진시키고 이에 적극적 으로 대처할 수 있도록 돕는 교사교육을 제공해야 할 것이다. $\operatorname{Kim}$ (2019)이 제안한 프로그램은 학교폭력 개념에 대한 학문 적 이해와 더불어 학교에서 제공되는 프로그램의 종류와 장, 단점 및 학교폭력 발생 시 어떻게 대처하고 사안을 처리해야 되는지 등에 대한 교육을 제공하고 있다. 따라서 이러한 프로 그램들을 예비교사 및 현직교사에게 제공하는 것은 학급 내에 가해행동을 허용하지 않는 분위기를 형성하고 괴롭힘이 발생 했을 때 교사가 적극적으로 개입하도록 함으로써 괴롭힘을 효 과적으로 중재할 수 있다.

연구문제 2 와 관련하여 학급 내 또래괴롭힘 허용분위기가 공정성에 대한 믿음과 방어행동 사이의 관계를 조절하는 지를 검증한 결과 학급 분위기는 자신에 대한 공정성 믿음과 방어 행동 간의 관계를 조절하는 것으로 나타났다. 구체적으로 학 급 내에서 또래괴롭힘을 허용하지 않는다고 지각한 아동이 자 신이 공정하게 대우받고 있다는 믿음수준이 높을수록 방어행 동을 더 많이 보였다. 이는 피해자를 돕는 행동이 공정한 행동 임을 알고 있지만 그러한 행동을 함으로써 자신에게 가해지는 위협이 크다고 지각한다면 실제 행동을 수행하지 않을 수 있 기 때문으로 해석할 수 있다. 반대로 학급 내에서 가해행동을 거부하고 피해자를 돕는 행동을 지지하는 분위기가 형성되어 있다면 이 행동을 수행함에 따른 위험이 적기 때문에 자신에 대한 공정성 믿음에 따라 방어행동을 보일 가능성이 높다는 것을 의미한다.

이에 기초해 볼 때 본 연구의 결과는 앞서 언급한 바와 같이 공정성에 대한 믿음을 높여주는 것이 방어행동 증진에 영향을 줄 수 있으나 공정성에 대한 믿음이 쉽게 변하지 않는 개인의 특성이기 때문에(Dalbert, 1999) 대안이 될 수 있는 방법으로 서 자신의 믿음에 따라 방어행동을 실제로 옮길 수 있도록 돕 는 학급 분위기를 형성하는 것이 효과적일 수 있음을 시사하 고 있다. 이는 아동에게 어린 시기부터 행동에 정당한 대가를 제공하고 이를 경험하게 함으로써 개인의 믿음 수준을 높이는 장기적인 방법과 더불어 단기적인 방법으로 학급 내에 가해행 동일 제지하고 피해자를 돕는 행동을 우선하는 분위기를 형성 함으로써 공정한 행동을 쉽게 수행할 수 있도록 하는 것이 또 래괴롭힘을 중재하는 데 효과적일 수 있음을 의미한다.

반면 타인에 대한 공정성 믿음과 방어행동 간의 관계에 대 한 또래괴롭힘 허용분위기의 조절효과는 유의하지 않았다. 이는 또래괴롭힘 상황은 명백하게 타인이 부당한 대우를 받 
는 상황이라는 점에 비추어 해석해 볼 수 있다. 선행연구에서 (Kogut, 2011) 타인에 대한 공정성 믿음이 피해자에 대한 도움 의도와 관계가 없었던 이유로 부당한 결과에 대한 피해자의 책임여부를 확인할 수 없었기 때문일 가능성이 있음을 고려했 을 때 피해를 직접 목격한 상황에서는 명백하게 부당한 대우 임을 인지할 수 있고 이로 인해 타인이 공정하게 대우받고 있 다고 믿는 믿음이 크게 위협받는 상황일 수 있다. 또한 자신의 믿음이 크게 위협받는 상황에서는 맥락에 관계없이 위협받은 믿음을 회복하는 데 도움이 될 수 있는 행동을 최우선으로 수 행하게 된다는 점에서(Dalbert, 2001) 타인의 공정성이 훼손되 는 또래괴롭힘을 목격하는 것은 타인에 대한 공정성 믿음을 크게 위협하는 상황이며 따라서 학급의 분위기에 관계없이 신 념에 따른 행동을 수행하기 때문에 조절효과가 나타나지 않은 것일 수 있다.

마지막으로 본 연구의 제한점을 밝히면서 후속연구를 위한 제언을 하면 다음과 같다. 첫째, 선행연구와 달리 자신에 대한 공정성 믿음이 방어행동에 유의한 영향을 주지 않은 것은 척 도의 문항 내용이 추상적이었던 것과 관련이 있을 수 있다. 일 부 문항은 “세상은 나를 공정하게 대한다.", "내가 경험하는 일 들은 대부분 정당한 편이다.” 등과 같이 초등학생들이 명확히 이해하기 다소 어려운 내용이었다. 따라서 추후 연구에서는 아동의 수준에 맞는 공정성에 대한 믿음을 측정할 수 있는 신 뢰로운 척도를 사용하여 조사할 필요가 있다. 예를 들어 아동 이 경험할 수 있는 공정성과 관련된 상황의 구체적인 예시를 사용하여 아동이 문항의 내용을 명확히 이해하고 적절히 응답 할 수 있도록 하는 것이 필요하다.

둘째, 학급 내 또래괴롭힘 허용분위기 척도의 신뢰도가 다 소 낮게 나타나 결과를 해석할 때 유의할 필요가 있다. 원척도 의 신뢰도가 낮은 것을 보완하기 위해 문항 평균을 다양화시 켰음에도 불구하고 척도의 신뢰도가 다소 낮게 나타난 점은 다음과 같이 이해할 수 있다. 본 척도에는 역채점 문항이 포함 되어 있어 초등학교 아동이 혼란을 느꼈을 수 있다. 또한 괴롭 힘 가해행동을 막아야 한다는 문항과 피해자를 도와야 한다는 문항이 모두 포함되어 비동질적인 구성으로 인해 신뢰도가 낮 게 나타난 것일 수 있다. 따라서 추후 연구에서는 초등학교 아 동이 쉽게 이해할 수 있도록 동질적인 문항과 함께 일관적인 채점 방향으로 구성한 척도를 사용하는 것이 효과적으로 적용 될 수 있을 것이다.

그러나 위와 같은 제한점에도 불구하고 본 연구가 지니는 시사점과 의의는 다음과 같다. 첫째, 본 연구는 공정성에 대한 믿음이 방어행동을 증진시키는 데 영향을 줄 수 있으며 특히
부정적인 행동과 관련된 것으로 주로 연구되어 온 타인에 대 한 공정성 믿음이 또래괴롭힘 상황에서는 피해자를 돕는 방어 행동과 관련될 수 있음을 보여주었다는 점에서 의의가 있다. 이는 직접적으로 피해자의 상황을 이해할 수 있는 또래괴롭힘 은 이를 목격하는 아동에게 적극적으로 행동하게 만들 수 있 기 때문에 어린 시기부터 가정과 학급에서 공정한 과정에 따 른 결과를 제공하는 것과 타인의 입장을 이해할 수 있도록 하 는 공감교육이 필요하다는 것을 시사한다. 둘째, 자신에 대한 공정성 믿음과 방어행동과의 관계에 대해 또래괴롭힘 허용분 위기가 조절효과를 갖는 것으로 나타난 본 연구의 결과는 학 급 내에서 또래들이 어떤 행동을 자주 하고 어떤 분위기를 형 성하느냐에 따라 자신이 가진 믿음의 수준이 방어행동에 주는 영향이 달라질 수 있음을 보여주었다. 특히 아동이 가지고 있 는 공정성에 대한 믿음은 비교적 일관적이기 때문에 이를 어 린 시기부터 형성하는 동시에 학급 내에서는 아동이 갖고 있 는 믿음의 효과를 극대화할 수 있도록 가해행동을 묵과하거나 용납하지 않는 분위기를 형성하는 것이 또래괴롭힘을 효과적 으로 중재하는 단기적 방법으로 적용될 수 있음을 시사했다는 점에서 의의가 있다.

\section{Notes}

This article is part of the first author's master's thesis submitted in 2020, and this article was presented as a poster at the 2019 Annual Fall Conference of the Korean Association of Child Studies.

\section{Conflict of Interest}

No potential conflict of interest relevant to this article was reported.

\section{References}

\section{In English}

Bègue, L. (2014). Do just-world believers practice private charity? Journal of Applied Social Psychology, 44(1), 71-76. doi:10.1111/ jasp. 12201

Bègue, L., \& Bastounis, M. (2003). Two spheres of belief in justice: Extensive support for the bidimensional model of belief 
in a just world. Journal of Personality, 71(3), 435-463. doi:10.1111/1467-6494.7103007

Caroli, M. E. D., \& Sagone E. (2014). Belief in a just world, prosocial behavior, and moral disengagement in adolescence. ProcediaSocial and Behavioral Sciences, 116, 596-600. doi:10.1016/ j.sbspro.2014.01.263

Cialdini, R. B., Baumann, D. J., \& Kenrick, D. T. (1981). Insights from sadness: A three-step model of the development of altruism as hedonism. Developmental Review, 1(3), $207-$ 223. doi:10.1016/0273-2297(81)90018-6

Correia, I., Kamble, S. V., \& Dalbert, C. (2009). Belief in a just world and well-being of bullies, victims and defenders: A study with portuguese and Indian students. Anxiety, Stress \& Coping, 22(5), 497-508. doi:10.1080/10615800902729242

Grotpeter, J. K., \& Crick, N. R. (1996). Relational aggression, overt aggression, and friendship. Child Development, 67(5), 2328-2338. doi:10.2307/1131626

Dalbert, C. (1999). The world is more just for me than generally: About the personal belief in a just world scale's validity. Social Justice Research, 12, 79-98. doi:10.1023/A:1022091609047

Dalbert, C. (2001). The justice motive as a personal resource: Dealing with challenges and critical life events. In Spinger (Series Ed.), Critical issues in social justice (Vol. 23). New York: Plenum Publishers.

Dalbert, C., \& Stoeber, J. (2006). The personal belief in a just world and domain-specific beliefs about justice at school and in the family: A longitudinal study with adolescents. International Journal of Behavioral Development, 30(3), 200207. doi:10.1177/0165025406063638

Donat, M., Umlauft, S., Dalbert, C., \& Kamble, S. V. (2012). Belief in a just world, teacher justice, and bullying behavior. Aggressive Behavior, 38(3), 185-193. doi:10.1002/ab.21421

Farmer, T. W., Lines, M. M., \& Hamm, J. V. (2011). Revealing the invisible hand: The role of teachers in children's peer experiences. Journal of Applied Developmental Psychology, 32(5), 247-256. doi:10.1016/j.appdev.2011.04.006

Fox, C. L., Elder, T., Gater, J., \& Johnson, E. (2010). The association between adolescents' beliefs in a just world and their attitudes to victims of bullying. British Journal of Educational Psychology, 80(2), 183-198. doi:10.1348/000709909X479105

Furnham, A. (2003). Belief in a just world: Research progress over the past decade. Personality and Individual Differences, 34(5), 795-817. doi:10.1016/S0191-8869(02)00072-7

Harmony Labs. (2015). Stand up: Virtual reality to activate bystanders against bullying (curriculum guide). New York: Harmony Labs.

Hawkins, D. L., Pepler, D. J., \& Craig, W. M. (2001). Naturalistic observations of peer interventions in bullying. Social Development, 10(4), 512-527. doi:10.1111/1467-9507.00178

Hayes, A. F. (2013). Introduction to mediation, moderation, and conditional process analysis: A regression-based approach. New York: Guilford Press.

Ingram, K. M., Espelage, D. L., Merrin, G. J., Valido, A., Heinhorst, J., \& Joyce, M. (2019). Evaluation of a virtual reality enhanced bullying prevention curriculum pilot trial. Journal of Adolescence, 71, 72-83. doi:10.1016/j.adolescence.2018.12.006

James, L. R., \& Sells, S. .B. (1981). Psychological climate: Theoretical perspectives and empirical research. In D. Magnusson (Ed.), Toward a psychological of situations: An interactional perspective (pp. 275-295). Hillsdale, New Jersey: Lawrence Erlbaum Associations.

Kogut, T. (2011). Someone to blame: When identifying a victim decreases helping. Journal of Experimental Social Psychology, 47(4), 748-755. doi:10.1016/j.jesp.2011.02.011

Kristof, A. L. (1996). Person-organization fit: An integrative review of its conceptualizations, measurement, and implications. Personnel Psychology, 49(1), 1-49. doi:10.1111/j.17446570.1996.tb01790.x

Lagerspetz, K. M. J., Björkqvist, K., Berts, M., \& King, E. (1982). Group aggression among school children in three school. Scandinavian Journal of Psychology, 23(1), 45-52. doi:10.1111/j.1467-9450.1982.tb00412.x

Lerner, M. J. (1980). The belief in a just world: A fundamental delusion. In Springer (Series Ed.), Critical issues in social justice (Vol. 23). New York: Plenum Press. doi:10.1007/9781-4899-0448-5

Lipkus, I. M., Dalbert, C., \& Siegler, I. C. (1996). The importance of distinguishing the belief in a just world for self versus others: Implications for psychological well-being. Personality and Social Psychology Bulletin, 22(7), 666-677. doi:10. 1177/0146167296227002

Ma, T.-L., \& Chen, W.-T. (2017). The benefits of being defended: Perceived bystander participant roles and victims' emotional and psychosocial adjustment. Journal of School Violence, 18(1), 77-91. doi:10.1080/15388220.2017.1387132

Messick, D. M., Bloom, S., Boldizar, J. P., \& Samuelson, C. D. (1985). Why we are fairer than others. Journal of Experimental Social Psychology, 21(5), 480-500. doi:10.1016/0022-1031 (85)90031-9

Mplus (Version 8.0). [Computer software]. Los Angeles, CA: Muthén \& Muthén.

O'connel, P., Pepler, D., \& Craig, W. (1999). Peer involvement in bullying: Insights and challenges for intervention. Journal of Adolescence, 22(4), 437-452. doi:10.1006/jado.1999.0238

Oberman, M.-L. (2011). Moral disengagement among bystanders to school bullying. Journal of School Violence, 10(3), 239257. doi:10.1080/15388220.2011.578276

Piliavin, I. M., Piliavin, J. A., \& Rodin, J. (1975). Costs, diffusion, and the stigmatized victim. Journal of Personality and Social Psychology, 32(3), 429-438. doi:10.1037/h0077092 
Pozzoli, T., \& Gini, G. (2010). Active defending and passive bystanding behavior in bullying: The role of personal characteristics and perceived peer pressure. Journal of Abnormal Child Psychology, 38, 815-827. doi:10.1007/s10802-0109399-9

Pozzoli, T., Gini, G., \& Vieno, A. (2012). The role of individual correlates and class norms in defending and passive bystanding behavior in bullying: A multilevel analysis. Child Development, 83(6), 1917-1931. doi:10.1111/j.1467-8624.2012.01831.x

Rigby, K., \& Slee, P. T. (1991). Bullying among Australian school children: Reported behavior and attitudes toward victims. The Journal of Social Psychology, 131(5), 615-627. doi:10.10 80/00224545.1991.9924646

Sallay, H., \& Dablert, C. (2004). The development of the belief in a just world: The impact of being raised in a one-parent or an intact family. In C. Dalbert \& S. Hedvig (Series Eds.), The justice motive in adolescence and young adulthood: Origins and consequences (Routledge research international series in social psychology, Vol. 8, pp. 26-42). NewYork: Routledge.

Salmivalli, C. (2010). Bullying and the peer group: A review. Aggression and Violent Behavior, 15(2), 112-120. doi:10.1016/ j.avb.2009.08.007

Salmivalli, C., Lagrespetz, K., Björkqvist, K., Österman, K., \& Kaukiainen, A. (1996). Bullying as a group process: Participant roles and their relations to social status within the group. Aggressive Behavior, 22(1), 1-15. doi:10.1002/ (SICI) 1098-2337(1996)22:1<1::AID-AB1>3.0.CO;2-T

Sutton, R. M., \& Winnard, E. J. (2007). Looking ahead through lenses of justice: The relevance of just-world beliefs to intentions and confidence in the future. British Journal of Social Psychology, 46(3), 649-666. doi:10.1348/014466606X166220

Strelan, P. (2007). The prosocial, adaptive qualities of just world beliefs: Implications for the relationship between justice and forgiveness. Personality and Individual Differences, 43, 881-890.

Ttofi, M. M., \& Farrington, D. P. (2011). Effectiveness of schoolbased programs to reduce bullying: A systematic and metaanalytic review. Journal of Experimental Criminology, 7, 2756. doi:10.1007/s11292-010-9109-1

\section{In Korean}

Ahn, T. (2016). The influence of emotional intelligence and the problem-focused coping on the defending behavior in bullying: Testing the moderated mediation effect of the belief in classroom norm. The Korean Journal of Elementary Counseling, 15(4), 341-362.

Cha, Y., \& Park, K. J. (2011). School children's roles and social understandings in peer bullying. Journal of Life-span
Studies, 1(1), 47-67.

Han, H., \& Oh, I. (2014). The relation between bystandners' behavioral reactions to bullying, gratitude, empathy, and a sense of school belonging. The Journal of Research in Education, 27(4), 53-75.

Jahng, S. (2015). Best practices in exploratory factor analysis for the development of the Likert-type scale. The Korean Journal of Clinical Psychology, 34(4), 1079-1100.

Jung, E., \& Ahn, D. (2017). Validations of the belief in a just world scale for adolescents. Journal of Learner-Centered Curriculum and Instruction, 17(16), 449-470. doi:10.22251/ jlcci.2017.17.16.449

Kim, K. (2019). Teacher education for school violence prevention: Focused on development of project-based prevention program. Journal of Learner-Centered Curriculum and Instruction, 19(17), 477-501. doi:10.22251/jlcci.2019.19.17.477

Lee, J., Kim, S., Cha, M., Lee, S., \& Park, Y. (2018). 2017 Jeongug haggyopoglyeog siltaejosa yeongu [2017 전국 학교폭력 실태 조사 연구]. Seoul: The Foundation for Preventing Youth Violet.

Lee, S.-G. (1999). Influencing factors on bullying at schools (Doctoral dissertation). Retrived from http://www.riss.kr/ link?id=T7133964.

Lim, C., \& Chung, O. (1997). The relationship between children's social competence and perceived peer relations. Korean Journal of Child Studies, 18(1), 163-175.

Lim, J.-Y. (1997). The influence of peer victimization on children's loneliness and anxiety (Master's thesis). Retrived from http:// www.riss.kr/link?id=T3427738

Ministry of Education. (2018). 2018nyeon 1cha haggyopoglyeog siltaejosa gyeolgwa [2018년 1차 학교폭력 실태조사 결과]. Retrieved from MOE website: https://www.moe.go.kr

Ministry of Education. (2019). Chodeunghaggyo dodeog 6 gyosayongjidoseo [초등학교 도덕 6 교사용지도서]. Seoul: Ministry of Education.

Moon, J., Kim, M., Kim, M., Kim, P., Seo, Y., Lee, M.,...Moon, H. (2012). Hakgyopongnyeok meomchwo!: bosalpim, Ujeong, baeumui gongdongche [학교폭력 멈춰!: 보살핌, 우정, 배움 의 공동체]. Seoul: Sallimteo.

Park, H. J., Han, M. Y., \& Kim, H. J. (2016). A study on effects of applications for the Aulim school violence prevention program. Korean Journal of Educational Research, 54(3), 121-150.

Park, M. Y. (2000). A study on factors influencing bullying behavior in primary school students (Master's thesis). Retrived from http://www.riss.kr/link?id=T8950601

Seo, M. (2008). Participation in bullying: Bystanders' characteristics and role behaviors. Korean Journal of Child Studies, 29(5), 79-96.

Shim, M., \& Seo, M. (2013). The class variables influencing on 
bystanding and defending behavior in bullying: Focusing on class norms and teacher's supervision. The Korea Journal of Youth Counseling, 21(2), 225-246.

Shon, K.-S., \& Lee, K.-M. (2015). A qualitative study of defenders' experiences in peer victimization. The Korean Journal of School Psychology, 12(3), 317-348.

Song, K., \& Lee, S. (2018). Children's moral reasoning and defending behavior in school bullying: The moderation effects of classroom level characteristics. The Korean Journal of Developmental Psychology, 31(2), 83-103.

Song, K., Son, Y. K., \& Lee, S. (2018). The structural relations among personal belief in a just world, cognitive reappraisal and defending behaviors in school bullying: The moderation effects of collective efficacy. The Korean Journal of School Psychology, 15(3), 489-509.

Yang, M., Kim, E., \& Lee, S. (2009). The effect of care enhancement program for the prevention of school violence in elementary students. The Journal of Elementary Education, 22(2), 205232.

\section{ORCID}

Seung-chul Lim http://orcid.org/0000-0003-4053-2549

Ju Hee Park http://orcid.org/0000-0003-3031-0272

Received December 30, 2019 Revision received February 2, 2020 Accepted February 8, 2020 